\title{
Brincadeira e
}

\section{Música: orientações necessárias}

Gislene Natera

nupeart 
Este trabalho pressupõe a complexidade do brincar e da música estarem presentes no cotidiano da educação básica. Primeiramente apresentam-se conceitos sobre brincadeira e brinquedos e um breve resumo de algumas pesquisas que se referem ao tema. Em seguida, apresentam-se algumas contribuições de educadores musicais que discutem música e brincadeira e as orientações nacionais. Conclui-se que o tema é rico, complexo e que ainda há muito espaço para debates e reflexões, porém, sente-se necessidade da inclusão de cursos de formação musical e pedagógico-musical para todos os educadores que atuam principalmente na educação infantil e anos iniciais do ensino fundamental.

\section{Introdução}

Há um menino, há um moleque morando sempre no meu coração

Toda a vez que o adulto "balança" ele vem pra me dar a mão. Há um passado no meu presente. Um sol bem quente lá no meu quintal, Toda vez que o adulto fraqueja o menino me dá a mão E me fala de coisas bonitas que eu acredito que não deixarão de existir Amizade, palavra, respeito, coragem, bondade, alegria e amor.... [Bola de Meia, Bola de Gude - Milton Nascimento e Fernando Brant]

B rincar é maravilhoso! Então, vamos começar. Um, dois, três: você quer brincar de que? Bola? Jogo de mãos? Roda? E a música pode ser uma brincadeira? Enquanto você pensa, vou explicar qual é a diferença entre brincadeira, brinquedo e jogo.

Para Vigostki (2008) ${ }^{1}$ a brincadeira é a linha principal do desenvolvimento na idade pré-escolar ${ }^{2}$ e é a realização de desejos, mas também de afetos generalizados. $\mathrm{O}$ autor afirma que não existe brincadeira em que não haja comportamento da criança submetido a regras, ou seja, qualquer brincadeira com situação imaginária tem regras e, qualquer brincadeira com regras é brincadeira com situação imaginária. Nesta concepção, a essência da brincadeira é uma nova relação entre a situação pensada e a situação real.

Já o brinquedo é o objeto para as crianças brincarem, como

${ }^{1}$ Tradução de Prestes, Zoia.

${ }^{2} \mathrm{O}$ autor refere-se à criança acima de 3 e até 6 ou 7 anos. 
afirma Brougère (1995), e o jogo, segundo Ferreira (1999), é a atividade física ou mental em sistemas de regras que definem a perda ou o ganho. É um passatempo. Brougère observa que a brincadeira humana supóe contexto social e cultural. Nessa concepção,

a brincadeira é um processo de relaçóes interindividuais, portanto de cultura [...] pressupóe uma aprendizagem social. Aprende-se a brincar. A criança pequena é iniciada na brincadeira por pessoas que cuidam dela, particularmente sua mãe [...]. A criança entra progressivamente na brincadeira do adulto, de quem ela é inicialmente o brinquedo, o espectador ativo e, depois, o real parceiro (BROUGÈRE, 1995, p. 97-98).

Kishimoto (1999) apresenta quatro possibilidades do brinquedo: Brinquedo educativo, Brincadeiras tradicionais infantis, Brincadeiras de faz de conta e Brincadeiras de construção. O Brinquedo educativo (ou jogo educativo) é aquele que possui fins pedagógicos e, segundo a autora, tem duas funçóes: a função lúdica quando o brinquedo propicia diversão, prazer e até desprazer, quando é escolhido voluntariamente; e a função educativa quando o brinquedo ensina qualquer coisa que complete o indivíduo em seu saber, seus conhecimentos e sua apreensão do mundo (p.37). São considerados, por exemplo, o quebra-cabeça, noçóes de sequencia, tabuleiro, móbiles, brincadeiras envolvendo músicas, danças, expressão motora entre outras.

Ao permitir a ação intencional (afetividade), a construção de representaçóes mentais (cognição), a manipulação de objetos e o desempenho de açóes sensório motoras (físico) e as trocas nas interaçóes (o social), o jogo contempla várias formas de representação da criança ou suas múltiplas inteligências, contribuindo para a aprendizagem e o desenvolvimento infantil (KISHIMOTO, 1999).

As Brincadeiras tradicionais infantis são aquelas filiadas à cultura popular. São associadas à cultura não oficial, desenvolvidas de modo oral e não cristalizadas, ou seja, são transmitidas de geração em geração, sendo que algumas brincadeiras mantêm suas estruturas iniciais, enquanto outras se modificam e recebem novos conteúdos, sem deixar de garantir a presença do lúdico, da situação imaginária. Entre muitas se encontram a amarelinha, o piáo e as parlendas.

As Brincadeiras de faz de conta também são conhecidas como simbólicas. São aquelas em que mais se evidencia a situação imaginária. 
Aparecem nestas brincadeiras o mundo social, a família, os pares e o currículo apresentado pela escola. "É alterando o significado de objetos, de situaçóes, é criando novos significados que se desenvolve a função simbólica, o elemento que garante a racionalidade ao ser humano" (KISHIMOTO, 1999, p. 39-40).

As Brincadeiras de construção "são consideradas de grande importância por enriquecer a experiência sensorial, estimular a criatividade e desenvolver habilidades da criança" (KISHIMOTO, 1999, p. 40). Neste caso, seriam brincadeiras onde a criança deve experimentar "o fazer". Ela deve ser estimulada a partir de algum material físico ou sonoro a criar novos brinquedos, jogos, objetos e regras. É o espaço para que a criança organize suas ideias, realize um planejamento para a construção do mesmo e construa algo funcional, palpável, concreto. Um bom exemplo seria a composição musical com diferentes possibilidades de arranjos, inclusive com a utilização de instrumentos alternativos.

\section{Pesquisas sobre a Brincadeira}

P esquisas nas diferentes áreas do conhecimento - educação, 1 educação física, psicologia, educação musical - mostram que a brincadeira ainda é um tema que necessita de muitas investigaçôes. A seguir, apresentaremos um pequeno resumo de alguns temas debatidos pelas diferentes áreas.

Silva (2011), pelo viés da educação, investigou os modos como os jogos, os brinquedos e as brincadeiras têm realizado o seu percurso histórico, sobre os espaços/tempos da brincadeira e sobre as práticas de permissão, transgressão e (re)produção do brincar, para, por meio desse conhecimento, aclarar as configurações sociais, atravessadas por desigualdades sociais e pela diversidade cultural, que permitem e ou inibem a afirmação das crianças como atores sociais e sujeitos produtores de cultura.

Silva e Homrich (2010) também realizaram um estudo que mostrou que as mudanças sociais que ocorreram na história influenciaram na formação da infância contemporânea e na relação desta com os brinquedos e brincadeiras, cabendo à escola a tarefa de articular passado e presente, assim como produzir reflexóes acerca das produçóes da atualidade. 
Já Santos, Matos e Almeida (2009), pelo viés da educação física, buscaram resgatar e trazer as brincadeiras tradicionais para o espaço escolar, para que essas desenvolvam aspectos físicos, cognitivos e sociais sem precisar fazer da aula de educação física algo monótono e tecnicista.

Gosso, Morais e Otta (2006) também constataram que crianças de diferentes culturas brasileiras mostram que os objetos naturais, os utensílios, os brinquedos manufaturados e objetos pouco estruturados se prestam a grandes transformações simbólicas. Desta forma, a pesquisa indica que através dos objetos as crianças refletem nas brincadeiras sua individualidade e os valores de sua cultura.

Resumidamente, as pesquisas mencionadas indicam que as brincadeiras desenvolvem aspectos físicos, cognitivos, imaginários e sociais, mas também são reflexos das condiçôes sociais em que as crianças experienciam, devendo a escola, como espaço privilegiado, resgatá-las e estimulá-las.

\section{Música e Brincadeira}

$\mathrm{N}$

a educação musical, Lydia Hortélio é um grande referencial para a área. Ela dedica-se ao estudo do brincar desde a década de 1970 e já acumulou mais de 3000 brinquedos de todo o mundo. Busca através de pesquisas e diferentes projetos o resgate e difusão da Cultura Tradicional da Infância onde a música é seu foco. A autora destaca a importância de a escola abrir mais espaço à expressão das crianças, sugerindo que a escola deva incluir a 'cultura do brincar'. Afirma que em seus cursos encontra educadores que se sentem aprisionados em sistemas político-pedagógico preocupados somente com os conteúdos. Dessa forma, afirma que:

A infância é algo precioso [...] a cultura popular é uma segunda infância. Um alemão extraordinário, Friedrich Schiller, diz que o homem só é inteiro quando brinca, e é somente quando brinca que ele existe na completa acepção da palavra homem. O brincar é algo espiritual. Eu sinto que [...] os brinquedos são a manifestação, a configuraçáo dessas necessidades. Por isso é que é preocupante as crianças não estarem brincando (HORTÉLIO, 2008, p. 24). 
Brito (2010), é outro exemplo na área de educação musical, pois em um de seus trabalhos ela discorre sobre o jogo relacional que deve se estabelecer entre a funcionalidade das ferramentas e a pseudoinutilidade dos brinquedos a partir de um texto de Rubem Alves. Desta forma, Brito se remete aos aspectos fundamentais da arte, mas também ao mundo dos significados e sentidos do mundo, interligando, música, educação e educação musical.

Delalande citado por Brito (2003, p. 31) afirma que música é jogo, e relaciona a atividade lúdica infantil proposta por Jean Piageta três dimensóes presentes na música: (1) jogo sensório-motor que é vinculado à exploração do som e do gesto; (2) jogo simbólico que é vinculado ao valor expressivo e à significação mesmo do discurso musical; e (3) jogo com regras que é vinculado à organização e estruturaçáo da linguagem musical. Como exemplo, o autor afirma que ao realizar um concerto podemos observar os três tipos de jogos:

O solista mostra seu virtuosismo mediante o jogo sensóriomotor, enquanto trechos musicais líricos constituem expressóes simbólicas. E toda a parte que diz respeito à estruturação da composição pode ser relacionada ao jogo com regras. (DELALANDE apud BRITO, 2003, p. 31).

Trazendo esses conceitos para as diferentes músicas e brincadeiras que aprendemos com nossos pais, professores e amigos, Brito (2003, p. 101) também ressalta que as parlendas e os brincos são as brincadeiras rítmico-musicais com que os adultos entretêm e animam os bebês e as crianças. Dessa forma, a autora afirma que as parlendas são as brincadeiras rítmicas com rima e sem música, e os brincos são, geralmente, cantados (com poucos sons), envolvendo também o movimento corporal (cavalinho, balanço...) e que junto com os acalantos, essas costumam ser as primeiras cançóes que intuitivamente cantamos para os bebês e crianças menores.

Mas ainda nos cabe mais uma questáo: $\mathrm{q}$ uais os elementos que definiriam uma música como infantil? Pescetti apud Beineke (2008, p. 6) refletindo sobre este assunto, afirma que existem três elementos fundamentais para que a música seja considerada infantil: (1) a letra da música deve se referir ao mundo infantil; (2) o trabalho com os elementos musicais deve ser reduzido/ essencial; 
e deve haver (3) a presença do jogo. Segundo o autor, não é necessária a existência de todos esses elementos, porém um deles deve ser mais significativo. Pescetti apud Beineke (idem, p. 7) privilegia o jogo, garantindo que a canção não precisa ser um jogo em si, mas que possibilite "o jogo com as palavras, com a linguagem musical ou com as possibilidades timbrísticas e interpretativas".

Dentro desta concepção, o lúdico em uma música existe quando se tem um clima infantil, ou seja, ela pode ser uma canção para adultos com letra que se refira ao universo infantil, ou uma letra de "adulto", mas que permita jogos musicais passíveis de serem assimilados pelas crianças.

\section{Orientações nacionais}

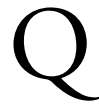

uais são as orientaçóes necessárias para que a música e a brincadeira estejam presentes na escola básica?

Em 20 de dezembro de 1996, foi promulgada a Lei de Diretrizes e Bases (LDB)- Lei 9.394/96 que realizou modificaçóes no ensino, dividindo a educação escolar em: Educação Básica e Educação Superior. Vale ressaltar que a mesma garante um espaço para a(s) Arte(s), estabelecendo que "o ensino da Arte constituirá componente curricular obrigatório, nos diversos níveis da educação básica, de forma a promover o desenvolvimento cultural dos alunos" (BRASIL, 1996, artigo 26). Neste sentido, em 1997, os PCN- Parâmetros Curriculares Nacionais, que não têm um caráter obrigatório, mas que se configuram em uma orientação oficial, propóem quatro modalidades artísticas: Artes Visuais, Música, Teatro e Dança, mas não há indicaçóes claras sobre como encaminhar essa abordagem na escola.

Uma das interpretaçóes possíveis sobre essa lei é que a escola pode decidir quais linguagens abordar, como e quando trabalhá-las (PENNA, 2008). Neste contexto, Figueiredo (2005) aponta também problemas decorrentes dos desdobramentos que a lei traz, ressaltando a inexistência de uma regularização do ensino das diferentes modalidades artísticas, dos conteúdos a serem trabalhados em cada série, da indicação sobre qual profissional será responsável pelo ensino da música e dos concursos públicos que excluíram os professores de música. 
Devido à necessidade que o governo brasileiro sentiu em oferecer e garantir a permanência das crianças a partir dos 6 anos na escola, no Brasil ela está se configurando com crianças mais novas, e consequentemente com mais possibilidades para a experiência do 'brincar' nos seus diferentes espaços. Neste sentido, é pertinente um breve relato sobre as leis e orientaçóes que transitam entre a estrutura da escola básica.

A Lei 11.114 de maio de 2005 (BRASIL, 2005) altera a LDB (BRASIL, 1996) no que refere à idade para ingresso obrigatório no Ensino Fundamental, passando dos sete para os seis anos. Em fevereiro de 2006, uma nova medida legal foi sancionada com uma alteração mais ampla da LDB com a Lei 11.274, na qual além da obrigatoriedade do ingresso no Ensino Fundamental a partir dos seis anos de idade, definiu-se que os sistemas deveriam ampliar o Ensino Fundamental para nove anos de duração, prevendo-se como prazo de implantação o ano de 2010.

A implementação do Ensino Fundamental de nove anos exigiu uma proposta pedagógica própria e um currículo novo, destacando-se as diversas expressóes das crianças e os conteúdos a serem ensinados e aprendidos. Em 2007, o Ministério da Educação, por meio da Secretaria de Educação Básica (SEB) e do Departamento de Políticas de Educação Infantil e Ensino Fundamental (DPE), elaborou um documento em forma de livro, intitulado "Ensino Fundamental de Nove Anos - Orientaçóes para a inclusão da criança de seis anos de idade", contendo nove textos, o qual busca fortalecer o debate com professores e gestores sobre a infância na educação básica, o que implica no conhecimento e respeito das características etárias, sociais, psicológicas e cognitivas das crianças.

E importante reconhecer que as orientações argumentam a favor da possibilidade da infância, do brincar como conteúdo pedagógico, do desenvolvimento da criança através das diversas expressões, assim como o trabalho por projetos como possibilidade de diálogos. O Referencial Curricular Nacional afirma que o brincar é uma das atividades fundamentais para o desenvolvimento da identidade e da autonomia, pois através dele a criança pode se comunicar e desenvolver algumas capacidades importantes como a atenção, a imitação e a imaginação. Ou seja, "é um espaço no qual se pode observar a coordenação das experiências prévias das crianças 
e aquilo que os objetos manipulados sugerem ou provocam no momento presente." (RCNEI, 1998, p. 23). Dentro dessa concepção, a brincadeira deve se constituir em uma oferta permanente e diversificada de atividades no espaço escolar, incluindo nela necessariamente os cantos para desenhar, para ouvir música, para manusear e ler livros, para jogos com regras etc.

Ainda sobre as leis e orientaçóes, em 2008, foi promulgada a Lei 11.769/2008 que altera a LDB estabelecendo que "a música deverá ser conteúdo obrigatório, mas não exclusivo, do componente curricular de que trata o $\$ 20$ deste artigo", ou seja, o ensino da arte. (BRASIL, 2008, parágrafo 6). Ou seja, atualmente é lei que a música esteja presente na escola básica (educação infantil ao ensino médio), porém não temos profissionais suficientes para tal abrangência e nem temos uma fiscalizaçáo legalizada sobre o assunto.

De forma geral, as professoras da educação infantil vêm assumindo a música como conteúdo auxiliar para a organização da rotina escolar (música para lavar as mãos, iniciar uma história, fazer fila etc.) e os professores do ensino fundamental e médio, como contribuinte para a integração com determinados conteúdos (como utilizar textos musicais para análise de construção de frases, músicas que contextualizam determinados períodos históricos etc.). Enfim, são variadas as maneiras e formas atuais da música estar presente na escola.

Porém, acreditamos que se os profissionais, principalmente os da educação infantil e dos anos iniciais, pudessem ter o contato, a vivência e a experiência do fazer musical durante sua formação, ou tivessem a possibilidade de realizar trabalhos em parcerias com os educadores musicais, o momento das brincadeiras e das músicas poderia contribuir ainda mais para a formação cultural das crianças. Isso significa dizer que, tanto a música como a brincadeira, podem e devem ser utilizadas no contexto escolar pelos professores de sala desde que isso aconteça com intencionalidade, com organização e com bases fundamentadas do por que ouvir ou tocar essa ou aquela música, ou brincar dessa ou de outra forma. 


\section{Algumas considerações}

$\mathrm{N}$

osso interesse neste trabalho não é trazer resposta ou verdade única e sim, convidar o leitor a refletir e a navegar em um mar de incertezas. É buscar que a música na escola básica seja uma linguagem capaz de se constituir como um modo de conhecer e de explicar a realidade. Para isso, consideramos que o espaço escolar deva possibilitar a ampliação do repertório musical, mas também valorizar, respeitar e favorecer as brincadeiras musicais de faz de conta, onde a criança possa criar, explorar e ressignificar cançóes do seu cotidiano, dando ênfase assim à experiência do brincar como cultura. É preciso também que as brincadeiras musicais de construção (jogos de improvisação) sejam estimuladas todos os dias, criando desdobramentos, redefinindo limites, possibilitando segurança para inovações e composiçóes, assim como o desenvolvimento de uma habilidade, que pode ser composicional ou instrumental.

Porém, como justificativas metodológicas, é comum a escola dizer que as crianças "aprendem brincando". Segundo Borba (2007) o brincar vem como um pretexto para o ensino de um determinado conteúdo e um bom exemplo seria a utilização de músicas para memorizar informaçóes, ou jogos para se aprender matemática, em que se perde o sentido da brincadeira. A autora afirma que devemos e podemos utilizar a ludicidade na aprendizagem, porém, quando a utilizamos para atingir resultados preestabelecidos, não se está garantindo a experiência da brincadeira como cultura. Nesta concepção, para garantir a experiência do brincar como cultura, precisamos centrar "a ação pedagógica no diálogo com as crianças e os adolescentes, trocando saberes e experiências, trazendo a dimensão da imaginação e da criação para a prática cotidiana de ensinar e aprender" (BORBA, 2007, p. 44).

Nesta perspectiva, não podemos negar que é bastante comum encontrarmos no ambiente escolar o Brinquedo Musical educativo, ou seja, a utilização da música com objetivos e resultados preestabelecidos. Um bom exemplo poderiam ser as cançóes para se andar em fila, lavar as mãos, tomar lanche, aprender a contar ou mesmo fortalecer o alfabeto.

Além do Brinquedo Musical Educativo, mas com menor ênfase, também encontramos o Brinquedo Tradicional, que são 
as músicas do folclore. Concordamos com a sua importância, pois elas possibilitam o resgate e a preservação das nossas raízes culturais e ainda possibilitam inúmeras atividades musicais. Porém, nossas experiências demonstram que quando se fala de música folclórica no espaço escolar, sempre nos referimos às 10 ou 15 músicas mais conhecidas como Marcha-Soldado, Atirei o pau no gato, Borboletinha, A linda rosa juvenil, Fui no mercado etc., nos esquecendo de outras 500 músicas talvez.

Queremos sugerir a reflexão não só na seleção de exemplos musicais que podem ir para a escola, mas junto disso, a necessidade de esclarecimento sobre o que selecionar, para que e por que selecionar este ou outro repertório. O repertório será legitimado no ambiente escolar dependendo do tratamento que o professor dará a ele. É necessário que o repertório tenha passado por uma seleção criteriosa, que ele tenha um valor musical e/ou educacional, que ele tenha um tratamento diferenciado e que ajude a formar uma sensibilidade auditiva (TOURINHO, 1993).

Por isso, sugerimos que os educadores responsáveis devam proporcionar à criança o contato com diferentes diversidades musicais para criar o hábito de ouvir, mas que também possibilite que ela brinque e experimente o prazer ou o desprazer; que desenvolva a percepção de elementos estruturais da obra musical; estimule-a a ter interesse em trazer e socializar suas brincadeiras musicais para o ambiente escolar provocando reflexóes sobre o contexto histórico e sociocultural no qual a música está inserida.

Consideramos, assim, que os Brinquedos Cantados e a ampliação do repertório são possibilidades da música estar presente de forma significativa na escola básica e que as diferentes experiências musicais, como imitar, repetir, improvisar, compor, escutar produçóes musicais de diferentes culturas, entre outras possibilidades, contribuem para que a criança conheça a si mesma e ao outro, para que se aproprie da música como linguagem, para que reelabore suas ideias e conceitos musicais, reconhecendo e distinguindo suas diferenças a fim de valorizar cada produção musical, mas também que a criança compreenda e respeite a pluralidade cultural, se perceba como produtora de cultura e que socialmente se posicione mais crítica, criativa e consciente sobre os produtos vendidos pela indústria cultural.

Para tanto, sabemos que existem inúmeras possibilidades 
de incorporar a ludicidade na aprendizagem e, que cabe ao professor planejar, propor, criar, experimentar novos caminhos, e ampliar as experiências deles próprios e das crianças para que a criança possa tecer seus conhecimentos de forma prazerosa.

Por isso, reivindicamos a inclusão de curso de formação musical e pedagógico-musical no currículo de todos os educadores que atuam principalmente na educaçáo infantil e nos anos iniciais, para que esses possam oferecer trabalhos significativos para as crianças. Da mesma forma, sugerimos que haja uma formação permanente para os profissionais que já estáo atuando.

Considerando as recentes orientações político-pedagógico e as reflexóes apresentadas anteriormente, defendemos a ideia de que o trabalho musical deva ser realizado no ambiente escolar de forma inter e multidisciplinar, ou seja, entre o professor de sala e o educador musical, enriquecendo desta forma a construção e a ampliação da experiência cultural das crianças, mesmo que o educador musical não seja o professor de música, mas que esteja presente neste ambiente como um coordenador ou assessor da área em questáo.

\title{
Brincando com música na sala de aula
}

\begin{abstract}
A seguir, apresentamos uma sugestão de canção que pode ser 1 usada como um Brinquedo Educativo (que tem objetivos preestabelecidos), mas que ao mesmo tempo possibilite à criança, o desenvolvimento do respeito à pluralidade cultural e estimule-a a ser criativa e crítica.
\end{abstract}

\section{Objetivos Específicos:}

Expressar com as mãos o ritmo da canção.

Vivenciar e marcar o pulso.

Marcar o compasso.

Identificar forma musical.

\section{Recursos Didáticos:}

Piano/ teclado ou violáo.

Fantoches de sapo.

Fantoches de borboletas.

Iô iô japonês. 


\section{O sapo e a borboleta}
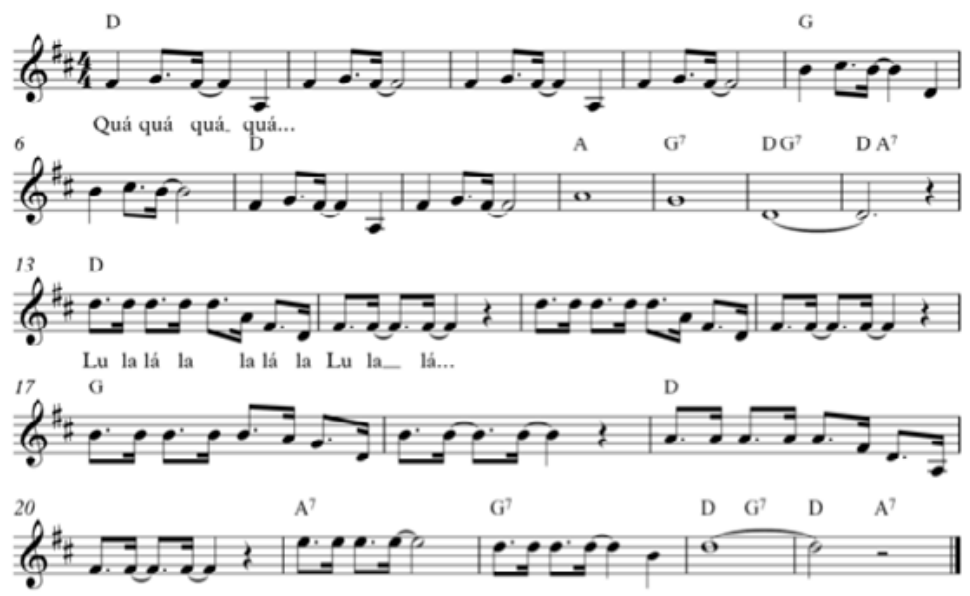

\section{Como se brinca:}

Lembrar as crianças que as vozes (onomatopeias) dos animais são diferentes de cultura para cultura. Ex: No Brasil o cachorro faz “au, au!" e nos Estados Unidos ele faz "woof, woof!" O sapo no Brasil faz "coach, coach" e na Alemanha fala "qua, qua".

I. Cantar a melodia do sapo, com o fantoche na mão (ritmo da canção).

Distribuir fantoches pajra algumas crianças e acompanhá-los tocando no piano.

ร. Apresentar o canto da borboleta, com a borboleta em mãos, marcando o pulso da canção.

Distribuir as borboletas e acompanhá-los ao piano.

Cantar em sequencia o canto do sapo e depois da borboleta.

I. Apresentar o acompanhamento de ambas as cançóes com a marcação do compasso no iô iô japonês.

Distribuir alguns e cantar toda a canção.

. Cantar parte $\mathrm{A}$ e $\mathrm{B}$, com seus respectivos brinquedos, mais iô iô japonês de suporte e depois cantar ao mesmo tempo (A e B)

. Pedir para cada um dos grupos (3) criarem uma expressão corporal enquanto se apresenta o arranjo já desenvolvido. 
$\int$ Escolher e decidir com as crianças como e de que forma se deve realizar o arranjo final, desde que o mesmo contenha os conceitos trabalhados (pulso, ritmo, compasso e expressão corporal).

$\int$ Possibilitar que as crianças criem novos arranjos nesta mesma canção, ou a partir de outro texto musical, pedir para que elas criem um arranjo, incluindo conceitos musicais, mas também a expressão performática.

\section{Referências}

BEINEKE, Viviane. Culturas infantis e produção de música para crianças: construindo possibilidades de diálogos. Actas do I Congresso em Estudos da Criança: Infâncias Possíveis, Mundos Reais. Universidade do Minho, Portugal, fev. de 2008.

BORBA, Ângela Meyer. O brincar como um modo de ser e estar no mundo. In: Ensino Fundamental de nove anos- orientaçóes para a inclusão da criança de seis anos de idade. Org. Beauchamp, J.; Pagel, S.D.; Nascimento, A. R. do. 2a Ed. Brasília, 2007. p. 33-45.

BRASIL. Ministério da Educação e Cultura. Referencial curricular nacional para a educação infantil/ Ministério da Educação e do Desporto, Secretaria de Educação Fundamental- Brasília: MEC/SEF, 1998.

Lei de Diretrizes e Bases da Educação Nacional 9394/96. Brasília, 1996.

Ministério da Educação e Cultura. Secretaria de Educação Fundamental. Parâmetros Curriculares Nacionais: arte. Brasília, 1997.

Ministério da Educação e Cultura. Secretaria da Educação Básica. Ensino Fundamental de Nove Anos: Orientaçóes para a inclusão da criança de seis anos de idade. 2a Ed. Brasília, 2007. Org. Beauchamp, J.; Pagel, S.D.; Nascimento, A. R. do. 
CNE/CEB n4/2008. Orientação sobre os três anos iniciais do Ensino Fundamental de nove anos.

Lei 11.114 , de 16/05/2005. Altera os artigos 6o, 30, 32 e 87 da Lei no 9394, de 20 de dezembro de 1996, com o objetivo de tornar obrigatório o início do ensino fundamental aos seis anos de idade.

Lei 11.769, de 18 de agosto de 2008. O art. 26 da Lei no 9.394, de 20 de dezembro de 1996, passa a vigorar acrescido do seguinte $\$ 6^{\circ} \mathrm{A}$ música deverá ser conteúdo obrigatório, mas não exclusivo, do componente curricular de que trata o $\$ 2$ o deste artigo." (NR)

BRITO, Teca de Alencar. Música na educação infantil. São Paulo: Peirópolis, 2003.

Ferramentas com brinquedos: a caixa da música. Revista da Abem, n. 24, set. 2010, p. 89-93.

BROUGÈRE, Gilles. Brinquedo e Cultura. São Paulo: Cortez, 1995.

FERREIRA, Aurélio Buarque de Holanda. Novo Dicionário Aurélio Século XXI: o dicionário da língua portuguesa. $3^{\mathrm{a}} \mathrm{ed}$. Rio de Janeiro: Nova Fronteira, 1999.

FIGUEIREDO, Sergio L. f. Educação musical nos anos iniciais da escola: identidade e políticas educacionais. Revista da Abem, n. 12, mar. 2005, p. 21-29.

HORTÉLIO, Lydia. É preciso brincar para afirmar a vida. In: Almanaque de cultura popular/ Papo cabeça. Out. 2008, p. 23-25.

KISHIMOTO, Tizuko Morchida. Jogo, brinquedo, brincadeira e a educação. 3. Ed. São Paulo: Cortez, 1999.

GOSSO, Yumi; MORAIS, Maria de L. S.; OTTA, Emma. Pivôs utilizados nas brincadeiras de faz-de-conta de crianças brasileiras de cinco grupos culturais. Estudos de Psicologia, 2006, vol. 11, p. 17-24. 
PENNA, Maura. Música(s) e seu ensino. Porto Alegre. Sulina, 2008.

PRESTES, Zoia. A brincadeira e seu papel no desenvolvimento psíquico da criança- Vigotski- Revista Virtual de Gestão de Iniciativas Sociais, p. 23- 36, junho, 2008.

SANTOS;Eliziane P. dos; MATOS, Felipe A. de; ALMEIDA, Cristina de. $\mathrm{O}$ resgate das brincadeiras tradicionais para o ambiente escolar. Movimento e Percepção, 2009, vol. 10.

SILVA, Alberto N. B. de A. e. Jogos, brinquedos e brincadeiras: trajectos intergeracionais. 2011, Tese de Doutorado. RepositóriUMUniversidade do Minho. Disponível em: http://repositorium.sdum. uminho.pt/handle/1822/13904 Acesso em dezembro, 2011.

SILVA, Daniela C. S.; HOMRICH, Marcele T. Brincadeiras e brinquedos na atualidade; breve contribuição articulando a infância e a escola. Reflexão \&Ação, 2010, vol. 18 (2), p. 198.

TOURINHO, Irene. Seleção de repertório para o ensino de música. Em pauta, 1993. 